Article

\title{
Residual Distribution Kinetics of Pesticides in Cherry Tomato Peel, Pulp, and Fruit as a Function of Irrigation Water Salinity, Household Rinsing, and Storage Regimen
}

\author{
Jakob A. Shimshoni ${ }^{1, *} \mathbb{1}$, Vijayakumar Bommuraj ${ }^{1}$, Yaira Chena ${ }^{1}$, Roy Sperling ${ }^{2}$, \\ Shimon Barel ${ }^{3}$, Yuval Kaye ${ }^{4}$ and Elazar Fallik ${ }^{5}$ \\ 1 Department of Food Quality \& Safety, Institute for Postharvest and Food Sciences, Agricultural Research \\ Organization, Volcani Center, 7505101 Rishon LeZiyyon, Israel; vijayakumar1669@gmail.com (V.B.); \\ chenyair@volcani.agri.gov.il (Y.C.) \\ Department of Instrumental Analytic, Bilacon GMbH, 13088 Berlin, Germany; roy.sperling@tentamus.com \\ Department of Toxicology, Kimron Veterinary Institute, 50250 Bet Dagan, Israel; Shimonba@moag.gov.il \\ Desert Agro-Research Center, Ramat-Negev R\&D, 85515 D. N. Halutza, Israel; yuval@mop-rng.org.il \\ Department of Postharvest Science, Institute for Postharvest and Food Sciences, Agricultural Research \\ Organization, Volcani Center, 7505101 Rishon LeZiyyon, Israel; efallik@volcani.agri.gov.il \\ * Correspondence: jakobs@volcani.agri.gov.il; Tel.: +972-50-6243961
}

Received: 11 November 2019; Accepted: 22 November 2019; Published: 24 November 2019

\begin{abstract}
The increased demand of high quantity and quality of cherry tomatoes requires the application of a wide range of pre-harvest pesticides. The application of dozens of pre-harvest pesticides frequently results in multiple pesticide residues, to which the end consumer is exposed. Incorrect usage of these pesticides may result in hazardous food contamination and therefore, it is crucial to monitor pesticide residues in pre- and post-marketed agricultural commodities. Hence, the objectives of the present study were to characterize the distribution and residual levels of pre-harvest pesticides applied on cherry tomatoes, as a function of regulated storage conditions, irrigation water salinity levels, and tap water rinsing. The fruits were grown in a greenhouse and were designated for the local and international markets. The residual pesticide levels allowed us to perform a dietary risk assessment for the consumption of contaminated tomatoes. Tetraconazole was the only pesticide residue, exceeding the maximal residue limit (MRL) value of $50 \mu \mathrm{g} / \mathrm{kg}$ in the fruits after 5 days of storage time. Since tetraconazole was shown to potentially impair reproduction and fetal development, it is suggested that the last application of this pesticide would be restricted to not less than 56 days before harvest. The extent of pesticide peel penetrability as well as the pesticide distribution and residual levels in the peel and pulp were unaffected by the salinity level (electrical conductivity $1.5-3 \mathrm{ds} / \mathrm{m}$ ) of the irrigation water. The most commonly applied household washing procedure for fruit and vegetables, using running tap water for $30 \mathrm{~s}$, was ineffective in removing residual pesticides from the peel. Hence, more efficient washing procedures are required to improve consumers' safety.
\end{abstract}

Keywords: distribution kinetics; pesticides; cherry tomatoes; storage; peel; pulp

\section{Introduction}

The steady increase in global demand of high quantity and quality of cherry tomatoes (i.e., Solanum lycopersicum var. cerasiforme, a type of a small tomato) necessitates the application of a wide range of pre-harvest pesticides (insecticides, fungicides, nematocides, and molluscicides) [1,2]. 
In Israel, cherry tomatoes constitute an essential part of fruit production and agricultural trade [3]. The application of dozens of pesticides during the growth process frequently results in multiple pesticide residues, to which the end consumer is exposed [4,5]. The toxicological hazard associated with long-term exposure to multiple pesticide residues in food commodities below their individual maximal residue limit (MRL) is of ongoing debate [5]. The European Union (EU) legislation lists 487 pesticides containing maximum residue limits (MRLs) for tomato [6]. In Israel, 99 synthetic organic pesticides are registered for pre-harvest usage on cherry tomatoes [7]. Incorrect usage of these pesticides may result in hazardous food contamination and therefore, it is crucial to monitor pesticide residues in pre-marketed agricultural commodities [5]. Various factors affect pesticide deposition and dissipation rate in agricultural commodities, such as concentration, treatment mode (spray or dip), type of mixture (aqueous- or wax-based mixtures), agricultural commodity, fruit age, treatment duration, temperature, and $\mathrm{pH}$ of the pesticide formulation [8,9]. The factors affecting the pesticide migration and distribution mechanism from peel to pulp include the peel's physico-chemical properties (lipophilic barrier covered with epicuticular waxes), the pulp's abundance of metabolizing enzymes, the pesticides' physico-chemical properties (octanol/water partition coefficient, acid/base dissociation constant, molecular weight, and water solubility), contact time between pesticides and matrixes, and the temperature $[8,9]$. Several studies clearly demonstrated that the usage of fresh irrigation water, as compared to salty irrigation water, led to increased pre-harvest as well as post-harvest fruit peel cracking [10]. The aforementioned observation raised the question whether the increase in fruit peel cracks due to irrigation with fresh water (electrical current $(E C)<2 \mathrm{ds} / \mathrm{m}$ ) [11] may result in increased penetrability of pesticides into the fruit pulp as compared to irrigation with salty water (EC $>3 \mathrm{ds} / \mathrm{m}$ ). Furthermore, storage duration and conditions (temperature, humidity) are known to have major impacts on fruit susceptibility to pests, fruit quality parameters, as well as on accumulation of pesticide residues [12]. Consequently, in order to minimize fresh produce loss of tomatoes and achieve pesticide residual levels below their MRL values, tomatoes in Israel are stored for a minimum of 5 days at $22{ }^{\circ} \mathrm{C}$ and humidity of $60 \%-85 \%$ prior to local marketing [13]. Tomatoes intended for export to the European Union are stored for 12 days at $12{ }^{\circ} \mathrm{C}$ in compliance with the European regulations [13]. In recent years, numerous studies have been conducted exploring efficient household-friendly washing solutions to remove residual pesticides from the peel of various fruits and vegetables [14-17]. The solutions differed in their $\mathrm{pH}$ values, detergent, salt, and bleaching concentrations. A common design to many of the aforementioned studies was the application of exaggerated washing time intervals (>1 min), which did not reflect common household washing procedures, being within the range of 10-60 s [14-17]. Furthermore, due to the large number of pre-and post-harvest pesticides and fresh produce, all of the studies were confined to a limited number of pesticides and/or fresh produce. Therefore, we have examined the removal efficiency of pesticide residues form the peel by a commonly applied washing procedure of fresh produce, namely by rinsing the produce under cold running tap water for $30 \mathrm{~s}$. The latter was crucial for performing risk assessment for tomato consumers.

To date, no published studies are available reporting the outcome of pesticide residues analysis, applied pre-harvest to cherry tomatoes, in peel, pulp, and fruit as a function of storage duration, irrigation water, and household water rinsing. Therefore, the objectives of the present study were to characterize the distribution and residual levels of pre-harvest pesticides in greenhouse-grown tomatoes, intended for the local and international markets. The characterization was done as a function of regulated storage conditions, irrigation water ("salty" vs. "fresh" water) and household tap water rinsing. The residual pesticide levels found on the 5th, 12th, and 14th day allowed us to perform a dietary risk assessment for the consumption of contaminated tomatoes. 


\section{Materials and Methods}

\subsection{Reagents}

Acetonitrile, glacial acetic acid, and formic acid (all HPLC grade) were obtained from Sigma-Aldrich (Saint Louis, MO, USA). Polymerically bonded ethylenediamine-N-propyl phase (PSA) was purchased from Varian (Palo Alto, CA, USA), while anhydrous magnesium sulfate, sodium chloride, anhydrous ammonium acetate, and C18 were purchased from Sigma-Aldrich (Saint Louis, MO, USA). All pesticide standards were of high purity grade (>99.0\%), purchased from Sigma-Aldrich (Saint Louis, MO, USA). Individual pesticide stock solutions were prepared at $1000 \mathrm{mg} / \mathrm{L}$ in acetonitrile or methanol and stored at $-20{ }^{\circ} \mathrm{C}$. The working solutions were prepared by carrying out appropriate dilutions of the stock solutions in acetonitrile.

\subsection{Plant Growth Experimental Design}

Cherry tomatoes (Solanum lycopersicum L.; cv. "Chocolate") were planted at the end of August 2018 in a non-heated plastic greenhouse (covered by polyethylene film $0.15 \mathrm{~mm}$ thick) in the Ramat Negev Agriculture Research Center, Israel ( $\left.30^{\circ} 57^{\prime} 54^{\prime \prime} \mathrm{N}, 34^{\circ} 42^{\prime} 02^{\prime \prime} \mathrm{E}\right)$. The plants were grown according to protocols commonly implemented by the local farmers. The substrate for seedling production consisted of $30 \%$ soil, $50 \%$ manure, and $20 \%$ peat and a small part of marble. All plants were irrigated using drip irrigation. A complete randomized block experimental design was used for the plantation periods with two experimental plot units per irrigation type, namely "fresh" irrigation water (EC $1.5 \mathrm{ds} / \mathrm{m}$ ) and "salty" irrigation water (EC $3 \mathrm{ds} / \mathrm{m}$ ). Each experimental plot unit had a surface area of $14 \mathrm{~m}^{2}$ that consisted of rows $7 \mathrm{~m}$ long and $2 \mathrm{~m}$ wide. During the entire growth period, 15 different pesticide formulations were applied mostly by spraying, according to the needs and growth protocol, containing all together 15 different pesticides as active ingredients (Table 1). The pesticide formulations applied were Dotan-Proplant ${ }^{\circledR}$ (Adama, Ashdod, Israel), Durivo SC ${ }^{\circledR}$ (Agrica, Hod-Hasharon, Israel), Perfect ${ }^{\circledR}$ (Tapazol, Beit-Shemesh, Israel), Mospilan ${ }^{\circledR}$ (Adama, Ashdod, Israel), Evisect- $S^{\circledR}$ (Agadot Agro, Ashdod, Israel), Pirate ${ }^{\circledR}$ (Luxembourg Industries Ltd, Tel-Aviv, Israel), Pegasus ${ }^{\circledR}$ (Gadot Agro, Ashdod, Israel), Bravo $^{\circledR}$ (Luxembourg Industries Ltd, Tel-Aviv, Israel), Polar ${ }^{\circledR}$ (Gadot Agro, Ashdod, Israel), Defender ${ }^{\circledR}$ (Adama, Ashdod, Israel), Score ${ }^{\circledR}$ (Agrica, Hod-Hasharon, Israel), Domark ${ }^{\circledR}$ (Luxembourg Industries Ltd, Tel-Aviv, Israel), Signum ${ }^{\circledR}$ (Adama, Ashdod, Israel), Rimon ${ }^{\circledR}$ (Adama, Ashdod, Israel) and Vitene ${ }^{\circledR}$ (Luxembourg Industries Ltd, Tel-Aviv, Israel). The timetable of tomato planting, pesticide application, and harvest is depicted in Table 1 . The timely application of each pesticide formulation was based on the initial emergence of the corresponding pest and the farmers' experience regarding the efficacy and availability of the pesticide's formulation. The pesticide application protocol depicted in Table 1 is frequently used in tomato farms in the Negev area of Israel.

Table 1. Time line of planting, pesticide application, and fruit harvest.

\begin{tabular}{|c|c|c|}
\hline Time & Route of Pesticide Application & Commercial Products (Concentration of Active Ingredient) \\
\hline \multicolumn{3}{|c|}{0 day: Planting } \\
\hline 12 days & irrigation water & $\begin{array}{c}\text { Dotan-Proplant }^{\circledR} \\
\left(722 \mathrm{~g} / \mathrm{L}^{\circledR} \text { of propamocarb }\right) \\
\text { Durivo SC }{ }^{\circledR} \\
(100 \mathrm{~g} / \mathrm{L} \text { chloranthraniliprole, } 300 \mathrm{~g} / \mathrm{L} \text { thiamethoxam })\end{array}$ \\
\hline \multicolumn{3}{|c|}{14 days: Initiation of Flowering } \\
\hline 16 days & spray & $\begin{array}{c}\text { Perfect }^{\circledR}(19.2 \mathrm{~g} / \mathrm{L} \text { emamectin benzoate }) \text { and Mospilan }{ }^{\circledR} \\
\text { (200 g/L acetamiprid) }\end{array}$ \\
\hline
\end{tabular}


Table 1. Cont.

\begin{tabular}{|c|c|c|}
\hline Time & Route of Pesticide Application & Commercial Products (Concentration of Active Ingredient) \\
\hline \multicolumn{3}{|c|}{21 days: Initiation of Fruit Formation } \\
\hline 26 days & spray & $\begin{array}{c}\text { Evisect- }^{\circledR} \\
(500 \mathrm{~g} / \mathrm{L} \text { thiocyclam-hydogene oxalate }) \text { and Pirate }{ }^{\circledR} \\
(240 \mathrm{~g} / \text { L chlorfenapyr })^{(2)}\end{array}$ \\
\hline 29 days & spray & $\begin{array}{c}\text { Pegasus }^{\circledR}(500 \mathrm{~g} / \mathrm{L} \text { diafenthiuron }) \text { and Bravo }{ }^{\circledR} \\
(720 \mathrm{~g} / \mathrm{L} \text { chlorothalonil })\end{array}$ \\
\hline 41 days & spray & Defender $^{\circledR}\left(215 \mathrm{~g} / \mathrm{L}\right.$ cyflumetofen) and Score ${ }^{\circledR}$ (difenoconazole \\
\hline 50 days & spray & $\begin{array}{l}\text { Evisect-S } S^{\circledR}(500 \mathrm{~g} / \mathrm{L} \text { thiocyclam-hydogene oxalate }) \text { and Domark }{ }^{\circledR} \\
(100 \mathrm{~g} / \mathrm{L} \text { tetraconazole }) \text { and Bravo }{ }^{\circledR}(720 \mathrm{~g} / \mathrm{L} \text { chlorothalonil })\end{array}$ \\
\hline 59 days & spray & $\begin{array}{l}\text { Signum }{ }^{\circledR} \\
(67 \mathrm{~g} / \mathrm{L} \text { pyraclostrobin, } 267 \mathrm{~g} / \mathrm{L} \text { boscalid })\end{array}$ \\
\hline \multicolumn{3}{|c|}{60 days: Initiation of Fruit Ripening } \\
\hline 67 days & spray & $\begin{array}{c}\text { Evisect-S }^{\circledR} \\
(500 \mathrm{~g} / \mathrm{L} \text { thiocyclam-hydogene oxalate })\end{array}$ \\
\hline 75 days & spray & $\begin{array}{c}\operatorname{Rimon}^{\circledR}(100 \mathrm{~g} / \mathrm{L} \text { novaluron }) \text { and Vitene }{ }^{\circledR}(450 \mathrm{~g} / \mathrm{L} \text { cymoxanil }) \\
\text { and Defender }{ }^{\circledR}(215 \mathrm{~g} / \mathrm{L} \text { cyflumetofen })\end{array}$ \\
\hline 83 days & spray & $\begin{array}{c}\text { Evisect-S }^{\circledR} \\
(500 \mathrm{~g} / \mathrm{L} \text { thiocyclam-Hydogene Oxalate })\end{array}$ \\
\hline 90 days & spray & $\begin{array}{c}\text { Signum }{ }^{\circledR} \\
(67 \mathrm{~g} / \mathrm{L} \text { pyraclostrobin, } 267 \mathrm{~g} / \mathrm{L} \text { boscalid }) ; \text { Vitene }^{\circledR} \\
(450 \mathrm{~g} / \mathrm{L} \text { cymoxanil })\end{array}$ \\
\hline
\end{tabular}

\subsection{Kinetics Study Design of Pesticide Distribution in Peel, Pulp, and Fruit}

Upon ripening, determined by visual inspection, $4 \mathrm{~kg}$ of each cherry tomato study group, differing by the irrigation water salinity level ("fresh" and "salty") were collected. The "fresh" and "salty" tomatoes were immediately transported back to the laboratory, and $1 \mathrm{~kg}$ of subsample was randomly retrieved from each study group and further processed for pesticide distribution analysis (time point: Day 0). The remaining fruits were immediately stored at $22{ }^{\circ} \mathrm{C}$ for 5 consecutive days in a dark confinement at $70 \%$ humidity (mimicking the Israeli storage guidelines for the local market). After 5 days of storage, a subsample consisting of $1 \mathrm{~kg}$ of "fresh" and "salty" fruits was taken for subsequent pesticide analysis (time point: Day 5). The remaining "fresh" and "salty" fruits were allocated to an adjacent storage room set to $12{ }^{\circ} \mathrm{C}$ and a humidity of $95 \%$ for 7 consecutive days (mimicking the EU storage guidelines for exported tomatoes). A subsample consisting of $1 \mathrm{~kg}$ of "fresh" and "salty" fruits was taken for subsequent pesticide analysis (time point: Day 12). The remaining tomatoes were ultimately allocated back to the "marketing" room operating at room temperature $\left(22^{\circ} \mathrm{C}\right)$ and humidity of $70 \%$ for 2 additional days, thereby mimicking the average shelf-life in commercial supermarkets in Israel (time point: 14 days).

At each time point, "fresh" and "salty" fruits were randomly divided into 3 subgroups, consisting each of 30 tomatoes. The peel of the first group $(n=30)$ was carefully removed by a curved thumb forceps and a scalpel blade and weighted separately for each tomato. The peel and pulp of 10 tomatoes were separately pooled together and homogenized (Ninja Nutri Shaker IQ, 1000 watts, Needham, MA, USA) as follows: Tomato peels (from 10 fruits) were diluted 1:3 (w/v) with double distilled water and homogenized for $1 \mathrm{~min}$, while 10 tomato pulps were homogenized without dilution for $1 \mathrm{~min}$. This process was repeated 3 times, yielding per subgroup three replicates. The second group of each tomato type ("fresh" and "salty") comprised unwashed fruits. The unwashed "fresh" and "salty" tomatoes, were divided into three replicates ( $n=10$ for each replicate) and homogenized for $1 \mathrm{~min}$ without dilution. The third group (washed tomatoes; $n=30$ ), consisting of "fresh" and "salty" tomatoes, was washed with running tap water ( $\mathrm{pH}$ of 6.6-6.8) applied for $30 \mathrm{~s}$ at a flow rate of $78 \mathrm{~mL} / \mathrm{s}$, intending to imitate how people wash tomatoes at home. The washed tomatoes were randomly divided into 3 subgroups, each consisting of 10 fruits. The fruits of each subgroup were separately homogenized 
without water dilution, yielding 3 repeats of homogenized washed and unpeeled tomatoes. All of the pooled homogenized samples were transferred to $50 \mathrm{~mL}$ falcon tubes and stored at $-80^{\circ} \mathrm{C}$ for up to 21 days until further analysis by LC-MS/MS. The aforementioned experiment was repeated twice as described above. The percentage of residual amount of pesticide on the peel was calculated as follows:

$$
\% \mathrm{C}_{\text {peel }}=\left(\mathrm{C}_{\text {peel }} \times \mathrm{f}_{\text {peel }}\right) /\left(\mathrm{C}_{\text {peel }} \times \mathrm{f}_{\text {peel }}+\mathrm{C}_{\text {pulp }} \times \mathrm{f}_{\text {pulp }}\right) \times 100
$$

With $C_{\text {pulp }}$ and $C_{\text {peel }}(\mathrm{mg} / \mathrm{kg})$ being the mean pulp and peel concentrations, respectively; $f_{\text {pulp }}$ and $f_{\text {peel }}$ representing the weight fraction of pulp and peel from total weighted fruit, respectively. The ratio of pesticide amount in peel to pulp was calculated as follows: Ratio $=C_{\text {peel }} \times f_{\text {peel }} / C_{\text {pulp }} \times f_{\text {pulp }}$

\subsection{Sample Preparation}

The QuEChERS procedure (AOAC Official Method 2007.01) was applied to the peel, pulp, and whole fruit samples. In brief, $10 \mathrm{~g}$ of thawed sample was placed in a $50 \mathrm{~mL}$ centrifuge tube; $10 \mathrm{~mL}$ of acetonitrile was added together with $4 \mathrm{~g}$ of $\mathrm{MgSO}_{4}$ and $1 \mathrm{~g}$ of $\mathrm{NaCl}$ and immediately shaken for $1 \mathrm{~min}$. The extract was centrifuged at $5000 \mathrm{rpm}$ for $5 \mathrm{~min}$. For the cleanup step, $5 \mathrm{~mL}$ of the upper organic layer was transferred into a $15 \mathrm{~mL}$ falcon tube, which contained a sorbent mixture composed of $250 \mathrm{mg}$ PSA and $750 \mathrm{mg}$ anhydrous $\mathrm{MgSO}_{4}$. The mixture was shaken for $1 \mathrm{~min}$ and then centrifuged at $5000 \mathrm{rpm}$ for $5 \mathrm{~min}$. Subsequently, $2 \mathrm{~mL}$ of the supernatant was transferred into a test tube and evaporated to dryness using at $40^{\circ} \mathrm{C}$ under a gentle stream of nitrogen. The remaining residue was reconstituted with $0.2 \mathrm{~mL}$ of acetonitrile. The reconstituted solution was subjected to centrifugation at $13,000 \mathrm{rpm}$ for $5 \mathrm{~min}$, and subsequently $0.1 \mathrm{~mL}$ was transferred into an injection vial to be analyzed by gas chromatography tandem-mass spectrometry (GC-MS/MS), while the remaining $0.1 \mathrm{~mL}$ acetonitrile was diluted with 1:1 with $1 \%$ formic acid in a DDW and subjected to LC-MS/MS analysis.

\subsection{Liquid Chromatography Tandem-Mass Spectrometry (LC-MS/MS) Analysis}

All analyses were performed on ACQUITY UPLC (ACQUITY UPLC, XEVO TQD mass spectrometer; Waters Corp., Milford, MA, USA), equipped with a quaternary pump and membrane degasser. The separation column, Zorbax SB-C18 $(2.1 \times 150 \mathrm{~mm}$ i.d. and $3.5 \mu \mathrm{m}$; Agilent Technologies, Santa Clara, CA, USA), was kept at $40{ }^{\circ} \mathrm{C}$. An automatic injector was set to inject $10 \mu \mathrm{L}$ per sample. The mobile phase components were (A) a $10 \mathrm{mM}$ ammonium acetate solution in water and (B) acetonitrile with $0.1 \%$ formic acid. The gradient used was initially set at a flow rate of $0.4 \mathrm{~mL} / \mathrm{min}$ of $95 \%$ mobile phase A for $0.25 \mathrm{~min}$. From $0.25 \mathrm{~min}$ to $7 \mathrm{~min}$, a linear gradient was used up to $95 \%$ mobile phase B, which was maintained for $1 \mathrm{~min}$. Then, a linear gradient was used to reach $95 \%$ mobile phase A, maintained for $1 \mathrm{~min}$. Sample analyses were performed using a triple quadrupole system with positive and negative Electro Spray Ionization (Table S1). The analytes were monitored and quantified using MRM mode. Optimization of the MS/MS conditions, identification of the parent and product ions, as well as the selection of the cone and collision voltages, were performed with direct infusion of their individual standard solutions (Table S1). The Masslynx software was used for the LC-MS/MS system control and data analysis.

\subsection{Gas Chromatography Tandem-Mass Spectrometry (GC-MS/MS) Analysis}

The analyses were carried out on a 7890 GC equipped with a 7693B auto sampler and a 7000 series GC-MS/MS system (Agilent Technologies, Palo Alto, CA, USA). A column HP-5MS UI $15 \mathrm{~m} \times 0.25 \mathrm{~mm}$ $\times 0.25 \mu \mathrm{m}$ (Agilent Ultra GC column) was used to provide analyte separation. Sample injections were performed in a 7890A GC multimode inlet operated using the splitless-injection mode through an inlet liner filled with a glass wool frit (Ultra Inert liner, obtained from Agilent, Santa Clara, CA, United States). The injector operating conditions were as follows: The injection volume was $2 \mu \mathrm{L}$, the injector temperature was held at $80^{\circ} \mathrm{C}$ during the solvent evaporation stage, then ramped up to $300{ }^{\circ} \mathrm{C}$ at $600 \mathrm{C} \mathrm{min}^{-1}$ and, finally, this temperature was held for $20 \mathrm{~min}$. Helium, with a purity of $99.999 \%$, 
was used as both the carrier gas and the quenching gas, and nitrogen with a purity of $99.999 \%$ as the collision gas. The oven temperature program was set as follows: $70^{\circ} \mathrm{C}$ for $1 \mathrm{~min}$, programmed to $150^{\circ} \mathrm{C}$ at $50{ }^{\circ} \mathrm{C} \mathrm{min}-1$, then to $200{ }^{\circ} \mathrm{C}$ at $6^{\circ} \mathrm{C} \mathrm{min}^{-1}$ and, finally, $280{ }^{\circ} \mathrm{C}$ at $16^{\circ} \mathrm{C} \mathrm{min}^{-1}$ (4.07 min). The total run time was $20 \mathrm{~min}$ plus three additional min to backflush at $280^{\circ} \mathrm{C}$. The triple quadrupole mass spectrometer was operated using electron impact ionization and in the selected reaction monitoring mode. The temperatures of the transfer line, ion source and quadrupole 1 and 2 were $280^{\circ} \mathrm{C}, 280^{\circ} \mathrm{C}$, and $150{ }^{\circ} \mathrm{C}$, respectively. The analysis was performed with a solvent delay of $2 \mathrm{~min}$ in order to prevent instrument damage. The electron multiplier voltage was set at $1592 \mathrm{~V}$. Mass peak widths were set to wide in the first and third quadrupoles. For control and data analysis, MassHunter B.05.00 software (Agilent, Santa Clara, CA, USA) was used. The two most intense mass transitions and their optimal collision energies were selected for pesticide quantification (Table S2). The most intense product was selected as the quantifier ion and the second as the qualifier ion. The collision gas flow was $1.5 \mathrm{~mL}$ $\mathrm{min}^{-1}$, and the quenching gas flow was $2.25 \mathrm{~mL} \mathrm{~min}^{-1}$. A 4-time-segment SRM method was created to obtain adequate sensitivity and signal-to-noise $(\mathrm{S} / \mathrm{N})$ relationship; the cycle time for each segment was set between 200 and $250 \mathrm{~ms}$.

\subsection{Dietary Risk Assessment of Contaminated Cherry Tomato Consumption}

Dietary risk assessment was performed for the individual pesticides as well as their summation, found in the cherry tomato samples. The health risk assessment was evaluated utilizing the "hazard quotient" (HQ) procedure [18]. The risk assessment for the oral exposure to the detected residues was based on the highest level of pesticide contamination found in fruits, calculated as follows:

$$
\begin{gathered}
\mathrm{ADI}=\left(\mathrm{C}_{\max } \times \mathrm{CR}\right) / \mathrm{B}_{\mathrm{W}} \\
\mathrm{HQ}=\mathrm{ADI} / \mathrm{RfD}
\end{gathered}
$$

where ADI is the average daily pesticide intake ( $\mathrm{mg} / \mathrm{kg} / \mathrm{day}), \mathrm{C}_{\max }$ is the mean pesticide concentration in tomato samples $(\mathrm{mg} / \mathrm{kg}), \mathrm{CR}$ is the mean tomato consumption rate $\left(\mathrm{kg} /\right.$ day), and $\mathrm{B}_{\mathrm{W}}$ is the average human body weight $(\mathrm{kg})$, which was defined as 60 and $15 \mathrm{~kg}$ for adults and children, respectively. $\mathrm{HQ}$ is the hazard quotient and RfD is the reference dose, defined as the maximum acceptable oral dose of a toxic substance $(\mathrm{mg} / \mathrm{kg} /$ day) [18]. The average daily consumption of tomatoes in Israel is $0.1399 \mathrm{Kg} /$ person/day, of which $30 \%$ is estimated to be cherry tomatoes [19]. Hence, we estimated the average daily consumption of cherry tomatoes in Israel to be $0.042 \mathrm{Kg} /$ person/day.

The HQs were calculated individually. Then the sum of the HQs was calculated (defined as the hazard index $=\mathrm{HI}$ ), which provides an estimation of the total risk of pesticide mixtures, assuming simple dose additivity [20]:

$$
\mathrm{HI}=\mathrm{HQ}_{1}+\mathrm{HQ}_{2}+\ldots \mathrm{HQ}_{\mathrm{n}}
$$

$\mathrm{HQ}$ and hazard index (HI) values below 1 are indicative of negligible health risk, while values $\geq 1$ indicate an increased health risk for consumers [18].

\subsection{Statistical Analysis}

Numerical results are presented as mean and standard deviation of the mean. Descriptive statistics were performed using statistical analysis program (GraphPad Prism version 5.00 for Windows, GraphPad Software, San-Diego, CA, USA). Two-way mixed ANOVA was performed between the following sub-groups: Rinsed vs. unrinsed fresh fruits; rinsed vs. unrinsed salty fruits; unrinsed fresh vs. unrinsed salty fruits; and rinsed fresh vs. rinsed salty fruits, in order to determine significant differences between the aforementioned sub-groups at a significant level of $p<0.05$ (GraphPad Prism version 5.00 for Windows, GraphPad Software, San-Diego, CA, USA). Significant interactions were explored with Bonferroni corrected post hoc tests. The two independent within and between 
group variables were storage time and matrix (washed and unwashed "fresh" and "salty" peel, pulp, and fruit).

Time-dependent changes in peel to pulp ratio of pesticide amounts were determined by linear regression F-test, utilizing the Excel software (Microsoft Excel 2016, Redmond, WA, USA), in which the difference of the slope from zero was set as the Null hypothesis, at a significance level of $p \leq 0.05$ (Table S3). An unpaired two-way $t$-test was performed between two linear regressions, namely fresh and salty peel/pulp pesticide amount ratio vs. time, in order to determine differences in regression slopes and intercepts between the two treatments (Table S3). Furthermore, a linear regression analysis was performed for the average peel residual pesticide concentration vs. their corresponding LogP values utilizing GraphPad software (GraphPad Prism version 5.00 for Windows, GraphPad Software, San-Diego, CA, USA). Log $P$ values were obtained from The US EPA web-based CompTox Chemistry Dashboard.

\section{Results and Discussion}

3.1. Decline of Pesticide Residues in Peel, Pulp, and Fruit as a Function of Storage Time, Irrigation Water, and Household Washing Procedure.

During the first 12 days of plant growth, the systemic fungicide propamocarb (Dotan-Proplant) and the insecticides, chloranthraniliprole, and thiamethoxam (Durivo) were applied through the irrigation water, while the remaining pesticide formulations were applied via foliage spraying during the remaining 78 days (Table 1). Among the 14 different pesticides, applied over the course of 90 days, only the following pesticides used over the time span of 87 days before harvest were detected in peel and pulp: Chloranthraniliprole (applied 87 days before harvest), difenoconazole (applied 58 days before harvest), tetraconazole (applied 49 days before harvest), novaluron (applied 24 days before harvest), cyflumetofen (applied 24 days before harvest), pyraclostrobin (applied 9 days before harvest), boscalid (applied 9 days before harvest), and cymoxanil (applied 9 days before harvest). The majority of the aforementioned pesticide residues, namely $62.5 \%$, belonged to the fungicide class (difenoconazole, tetraconazole, boscalid, cymoxanil, pyraclostrobin), while the remaining $37.5 \%$ belonged to the insecticidal/acaricidal class (chloranthraniliprole, novaluron and cyflumetofen). Figure 1 depicts the pesticide residue levels in peel, pulp, and fruit as a function of irrigation water ("salty" and "fresh") as well as the storage duration and tap water rinsing. Among the pesticides applied in the present study, only boscalid, pyraclostrobin, and tetraconazole displayed residual peel concentrations in both "fresh" and "salty" fruits exceeding the MRL values, as defined for the fruit during the entire storage period of 14 days (Figure 1). Moreover, tetraconazole was the only pesticide exceeding the MRL value of $50 \mu \mathrm{g} / \mathrm{kg}$ in one out of three repeats in the whole fruit "salty" tomatoes (namely $55 \mu \mathrm{g} / \mathrm{kg}$ ) after 5 days of incubation time at room temperature. However, after 12 days of storage, tetraconazole residual levels decreased in all of the analyzed peel, pulp, and whole fruit below the MRL of $50 \mu \mathrm{g} / \mathrm{kg}$, thereby complying with the European Union regulations (Figure 1). The European Commission defined an acceptable daily intake (ADI) for tetraconazole of $0.004 \mathrm{mg} / \mathrm{kg}$ body weight/day based on the no-observed-adverse-effect level (NOAEL) obtained in a 2-year rodent study [21]. In a worst-case scenario, the exposure of consumers to the highest tetraconazole concentration found in tomatoes $(55 \mu \mathrm{g} / \mathrm{kg})$ results in a daily exposure of $2.31 \mu \mathrm{g}$ tetraconazole. The latter value is 25 and 100 times lower than the defined ADI for children (weighting $15 \mathrm{~kg}$ ) and adults (weighting $60 \mathrm{~kg}$ ), and therefore no health hazards are expected upon tetraconazole exposure. Notwithstanding, since tetraconazole has been demonstrated to potentially impair fetal development and reproduction in chronic studies in rats and mice, it is suggested to restrict the last application of tetraconazole to 56 days before harvest, in order to avoid exceeding the MRL value of $50 \mu \mathrm{g} / \mathrm{kg}$ as is demonstrated in the present study (Table 1, Figure 1). 


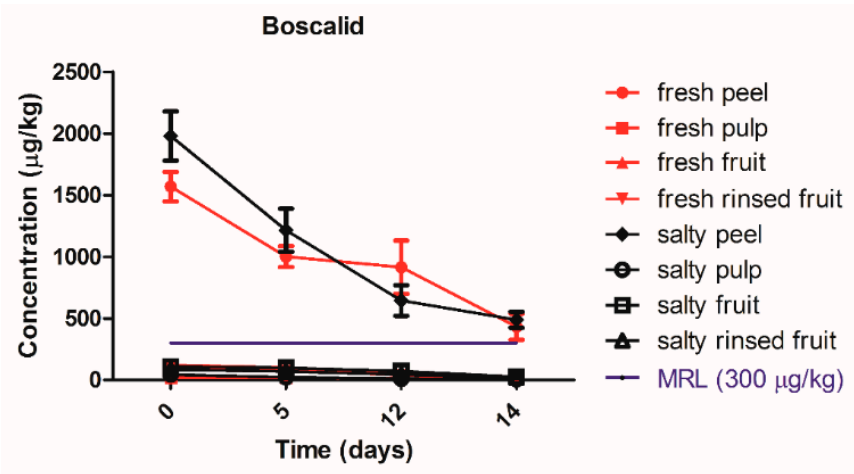

Chloranthraniliprole

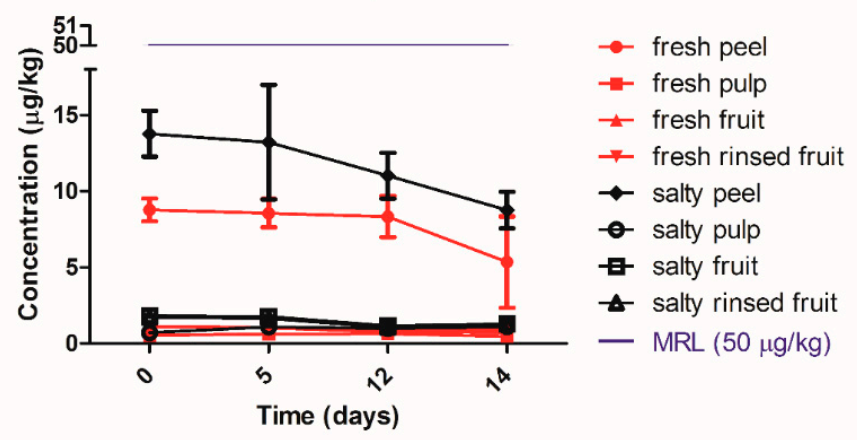

Cyflumethofen

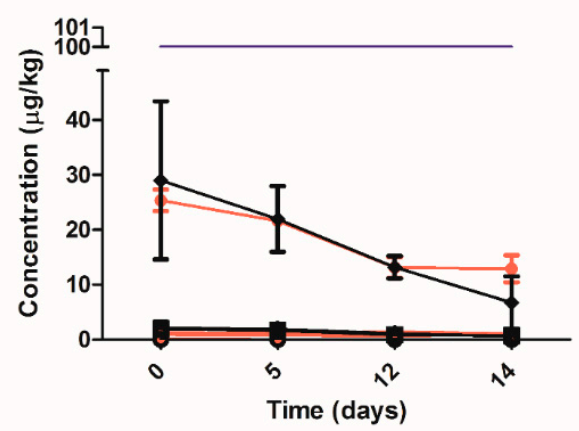

$\rightarrow$ fresh peel

- fresh pulp

$\star$ fresh fruit

* fresh rinsed fruit

$\rightarrow$ salty peel

- salty pulp

\# salty fruit

¿ salty rinsed fruit

- MRL $(100 \mu \mathrm{g} / \mathrm{kg})$

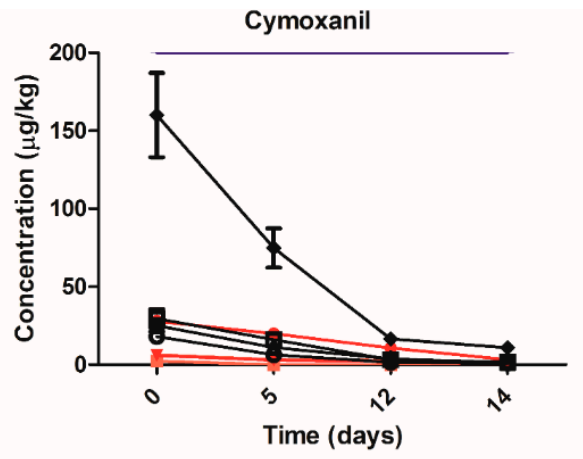

Figure 1. Cont.

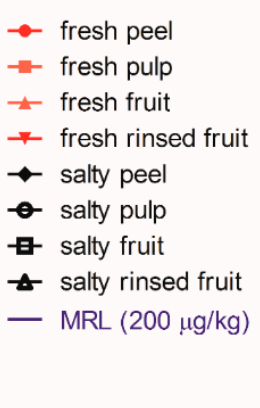

$\rightarrow$ fresh peel

- fresh pulp

$\_$fresh fruit

$\downarrow$ salty peel

- salty pulp

\# salty fruit

salty rinsed fruit

Time (days) 

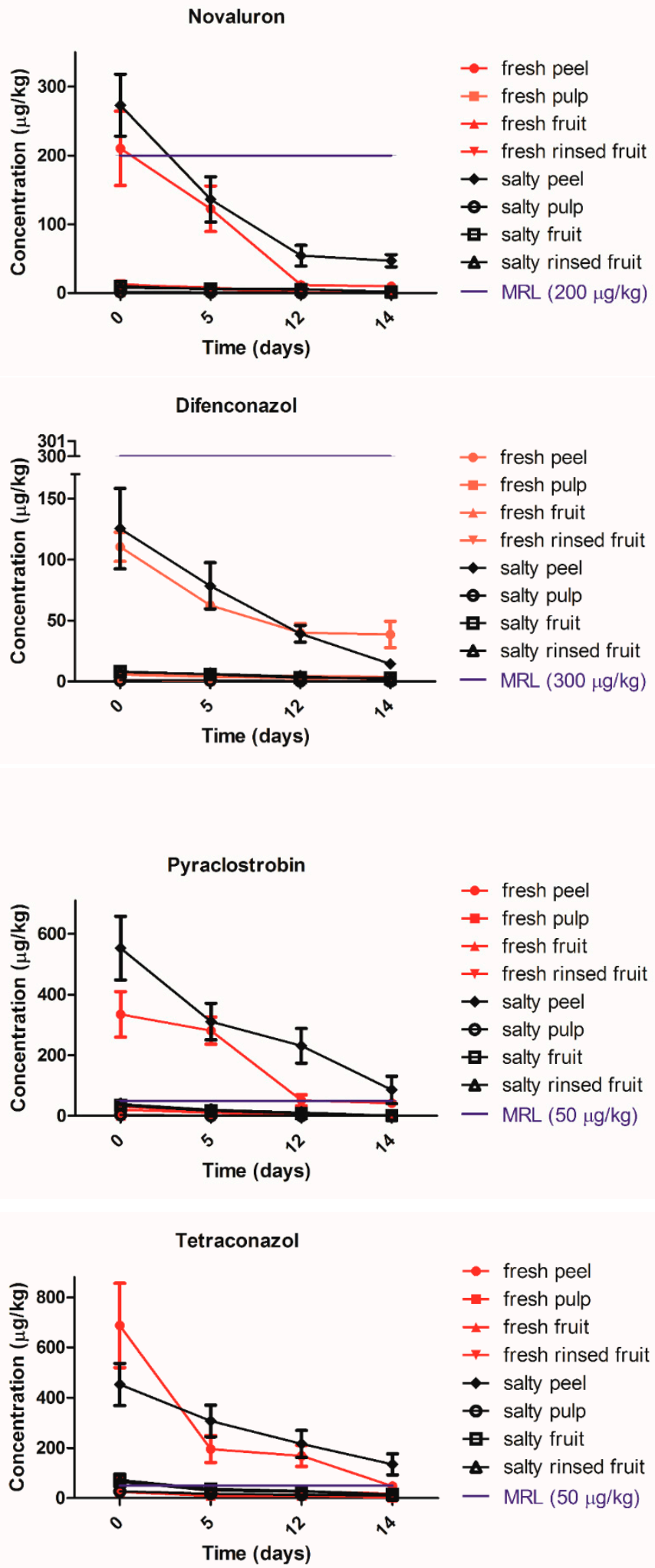

Figure 1. Pesticide distribution and concentration decline as a function of time in peel, pulp, and whole cherry tomato fruit irrigated with fresh or salty water. 
The residual levels of the remaining pesticides were found to be below the MRL values for the whole "fresh" and "salty" fruits, thereby complying with the Israeli and European regulations $[6,22]$. A previous study indicated a negative correlation between the extent of tomato fruit cracking and the mineral content of irrigation water [10]. Hence, we hypothesized that the tomatoes irrigated with the "fresh" water will display a higher proportion of peel cracking, resulting in higher penetrability of pesticides into the pulp. Our results indicated that the extent of penetrability of pesticides into the pulp was unaffected at a fresh water salinity levels of EC 1.5-3 ds/m (Table 2). However, a higher pesticide penetrability into the pulp could not be ruled out at salinity level below EC $1.5 \mathrm{ds} / \mathrm{m}$. This, however, needs to be confirmed in a separate study.

Table 2. Statistical comparison (mixed ANOVA) of mean pesticide values ( $\mu \mathrm{g} / \mathrm{kg} \pm$ standard deviation) of water rinsed ${ }^{1}$ vs. unrinsed ${ }^{2}$ fresh and salty tomatoes during the entire storage duration.

\begin{tabular}{|c|c|c|c|c|c|}
\hline Storage Time & (1) Fresh Fruit & $\begin{array}{l}\text { (2) Rinsed } \\
\text { Fresh Fruit }\end{array}$ & (3) Salty Fruit & $\begin{array}{l}\text { (4) Rinsed } \\
\text { Salty Fruit }\end{array}$ & Statistical Analysis ${ }^{3}$ \\
\hline \multicolumn{6}{|c|}{ Boscalid } \\
\hline 5 & $101 \pm 10$ & $75 \pm 16$ & $99 \pm 28$ & $70 \pm 11$ & No statistically significant difference \\
\hline 12 & $62 \pm 13$ & $41 \pm 9$ & $71 \pm 16$ & $45 \pm 16$ & No statistically significant difference \\
\hline 14 & $14 \pm 1.9$ & $15 \pm 6$ & $25 \pm 8$ & $20 \pm 7$ & No statistically significant difference \\
\hline 5 & $1.0 \pm 0.3$ & $1.1 \pm 0.3$ & $1.7 \pm 0.2$ & $1.6 \pm 0.2$ & No statistically significant difference \\
\hline 12 & $0.9 \pm 0.1$ & $0.7 \pm 0.2$ & $1.2 \pm 0.3$ & $1.0 \pm 0.1$ & No statistically significant difference \\
\hline 14 & $0.9 \pm 0.3$ & $0.7 \pm 0.1$ & $1.2 \pm 0.2$ & $1.3 \pm 0.3$ & No statistically significant difference \\
\hline \multicolumn{6}{|c|}{ Cyflumethofen } \\
\hline 0 & $1.3 \pm 0.4$ & $0.8 \pm 0.2$ & $1.9 \pm 1.2$ & $2.1 \pm 1.2$ & No statistically significant difference \\
\hline 0 & $6.4 \pm 0.8$ & $5.9 \pm 0.5$ & $4.9 \pm 0.5$ & $6.0 \pm 0.6$ & No statistically significant difference \\
\hline 5 & $3.3 \pm 0.5$ & $2.9 \pm 0.2$ & $3.2 \pm 0.4$ & $3.8 \pm 0.8$ & No statistically significant difference \\
\hline 12 & $2.7 \pm 0.7$ & $2.2 \pm 0.3$ & $1.6 \pm 0.6$ & $1.2 \pm 0.1$ & No statistically significant difference \\
\hline 14 & $0.4 \pm 0.3$ & $0.3 \pm 0.2$ & $0.2 \pm 0.3$ & $0.5 \pm 0.2$ & No statistically significant difference \\
\hline \multicolumn{6}{|c|}{ Difenconazole } \\
\hline 0 & $6.2 \pm 0.9$ & $5.6 \pm 1.4$ & $8.0 \pm 1.5$ & $7.6 \pm 1.0$ & No statistically significant difference \\
\hline 5 & $4.9 \pm 0.9$ & $3.8 \pm 0.6$ & $5.9 \pm 2.0$ & $6.2 \pm 0.6$ & No statistically significant difference \\
\hline 12 & $4.5 \pm 1.5$ & $2.7 \pm 0.5$ & $3.0 \pm 0.8$ & $4.0 \pm 1.0$ & No statistically significant difference \\
\hline 14 & $3.7 \pm 0.4$ & $2.1 \pm 0.5$ & \multirow{2}{*}{\multicolumn{2}{|c|}{ Novaluron }} & No statistically significant difference \\
\hline 0 & $11.6 \pm 2.0$ & $12.9 \pm 5.2$ & & & No statistically significant difference \\
\hline 5 & $8.0 \pm 3.0$ & $6.4 \pm 1.0$ & $5.9 \pm 2.8$ & $6.1 \pm 2.0$ & No statistically significant difference \\
\hline \multicolumn{6}{|c|}{ Tetraconazole } \\
\hline 0 & $67 \pm 16$ & $72 \pm 19$ & $73 \pm 23$ & $65 \pm 11$ & No statistically significant difference \\
\hline 5 & $29 \pm 13$ & $31 \pm 15$ & $37 \pm 18$ & $30 \pm 14$ & No statistically significant difference \\
\hline 12 & $28 \pm 9$ & $26 \pm 9$ & $29 \pm 11$ & $27 \pm 11$ & No statistically significant difference \\
\hline 14 & $14 \pm 3$ & $18 \pm 6$ & $15 \pm 9$ & $12 \pm 6$ & No statistically significant difference \\
\hline
\end{tabular}

${ }^{1}$ Fruits were rinsed with running tap water for 30 seconds. ${ }^{2}$ Fruits were analyzed for pesticide residues without prior water rinsing. ${ }^{3}$ Statistical analysis (two-way mixed ANOVA) was performed between the following sub-groups: Rinsed vs. unrinsed fresh fruits; rinsed vs. unrinsed salty fruits; unrinsed fresh vs. unrinsed salty fruits; and rinsed fresh vs. rinsed salty fruits. No statistically significant differences were found between the subgroups, rinsed and un-rinsed "fresh" fruits and rinsed and un-rinsed "salty" fruits, during the entire storage duration. 
A common household washing procedure for fruit and vegetable, namely washing with running tap water ( $\mathrm{pH}$ of $6.6-6.8 ; 26^{\circ} \mathrm{C}$ ) applied for $30 \mathrm{~s}$, was ineffective in removing residual levels of boscalid, chloranthraniliprole, cyflumethofen, cymoxanil, difenoconazole, novaluron, pyraclostrobin, and tetraconazole from the peel (Table 2). No statistically significant differences were found between the subgroups, rinsed and un-rinsed "fresh" fruits and rinsed and un-rinsed "salty" fruits (Table 2), during the entire storage duration. Possible explanations for the observed lack of removal efficiency is that the majority of the detected pesticides (except cymoxanil) are highly lipophilic $(\log P>2.8)$, resulting in higher partitioning/adsorption into the lipophilic matrix components within the peel (cutin, lipophilic fibers, lycopene) as compared to their tendency to partition into water [23,24]. Notwithstanding, the water-soluble cymoxanil is more hydrophilic than the other pesticides with a LogP value of 0.67 [25]. The inefficient removal of cymoxanil by water rinsing might be the result of deeper peel penetration of cymoxanil residues, which cannot be removed by simple washing procedures, as was demonstrated for pesticides of various physico-chemical properties and mode of action such as phosmet, thiabendazole, and ferbam $[24,26]$.

In recent years, numerous studies compared the removal capacity of a limited number of pesticides by different aqueous solutions such as tap water, acetic acid solutions, baking soda solutions, dishwashing solutions, as well as bleach and acetic acid peroxides [14-17,20,24]. Furthermore, additional parameters were evaluated in aiding the aqueous solutions in reducing residual pesticide levels from the peel, such as temperature, sonication, $\mathrm{pH}$, and addition of $\mathrm{NaCl}$ to the aqueous solutions $[14-17,20,24]$. No single treatment was found to significantly remove all of the studied pesticides from the peel. The lack of a user-friendly household rinsing solution capable of removing more than $50 \%$ of all residual pesticides from the peel is not surprising, due to the fact that pesticides significantly differ in their physico-chemical properties, and their removal further depends upon numerous variables such as the washing solution, washing duration, pesticide's chemical property, the surface area, the nature of the food, the length of time the pesticide is in contact with the food, and the formulation and application method of the pesticide $[14-17,20,24]$.

Furthermore, there was no correlation observed between aqueous solubilities of the studied pesticides and the removal capacity from the peel $[14-17,20,24]$. However, an interesting negative correlation was observed between their logarithmic octanol-water coefficients (LogP values) and their peel rinsability $[14-17,20,24]$. The latter observation indicates that the more lipophilic pesticides adhere more strongly to the lipophilic peel cuticle, resulting in higher resistance to their removal by aqueous washing solutions. Usually, the pesticide is lodged in the outer wax-like layers and then moves to the inside, making washing and removal of the pesticides less effective [14-17,20,24]. Notwithstanding, based on the aforementioned studies, a common denominator was found for significant removal of numerous studied pesticides from the peel, namely rinsing with hot water, dishwashing soap solution, as well as washing in an ultrasonic bath. To the best of our knowledge, the effective removal of pesticide residues from the peel of agricultural produce has been tested only for a very limited number of pesticides and agricultural products, and therefore a substantial knowledge gap exists in that regard.

\subsection{Pesticide Peel to Pulp Ratio}

Pesticide residual levels in peel and pulp of fresh produce stored under controlled environmental conditions (temperature, humidity, and darkness) are primarily affected by pesticide distribution behavior between peel and pulp and by the pesticide's dissipation kinetics, governed by two processes: Abiotic chemical degradation (such as hydrolysis and redox-reactions) and biotic metabolic degradation $[8,9,27]$. The biotic metabolic degradation occurs through intracellular enzymes within the pulp and/or by microorganisms (fungi, bacteria) present primarily on the peel (e.g., cytochrome P450, peroxidases, amidases) [27]. Furthermore, it has been demonstrated that the metabolic fate of pesticides depends on abiotic environmental conditions (e.g., temperature, moisture, soil $\mathrm{pH}$ ), microbial community and/or plant species, pesticide characteristics (molecular weight, hydrophilicity, $\left.\mathrm{pK}_{\mathrm{a}}, \log \mathrm{P}\right)$ [27]. 
Table 3 depicts the mean peel/pulp ratio (Rp) of pesticide amount determined in "fresh" and "salty" tomatoes over the entire storage time, as well as the change of Rp as a function of storage time. Among the eight detected pesticide residues, chloranthraniliprole, cyflumetofen, and tetraconazole revealed a significant decline in their $\mathrm{Rp}$ value as a function of storage time, while only pyraclostrobin displayed a significant increase in its $\mathrm{Rp}$ value throughout the study duration (Table 3, Table S3). The Rp decline observed for chloranthraniliprole, cyflumetofen, and tetraconazole is the result of a higher pesticide dissipation rate in the peel as compared to the pulp, while for pyraclostrobin the opposite phenomenon was observed (Figure 1). A higher pesticide dissipation rate in the peel as compared to the pulp, might be the result of a higher pesticide susceptibility to abiotic degradation processes and/or microbial degradation in the peel. On the other hand, a higher pesticide degradation rate in the pulp might be related to a faster pesticide metabolism by intracellular enzymes within the pulp as compared to the dissipation rate in the peel [27]. The remaining pesticides, namely boscalid, cymoxanil, difenoconazole, and novaluron, exhibited Rp values independent of storage duration, hence at steady-state (rate of dissipation in peel and pulp are equal; Table 3, Table S3). Moreover, no significant changes were observed in the pesticide dissipation kinetics and Rp values between "fresh" and "salty" tomatoes (Table 3 and Table S3). Consequently, it seems that within the irrigation water salinity range of EC 1.5-3 ds/m, no significant effect on pesticide distribution and dissipation in peel, pulp and fruit was found. However, it is reasonable to assume that at salinity levels below EC $1.5 \mathrm{ds} / \mathrm{m}$, the tendency of fruit cracking is increased, which may lead to enhanced pesticide penetration into the pulp.

The detected pesticides displayed a wide range of Rp values (1.5-2694), with cyflumetofen displaying the highest Rp value (2694 in "fresh" tomatoes), while cymoxanil revealed the lowest Rp value (1.5 in "fresh" tomatoes) (Table 3). The exceptionally large Rp value of cyflumetofen can be attributed primarily to the undetected residues in the pulp. The Rp value of cyflumetofen could be calculated only by substituting the undetected pulp concentrations with half of cyflumetofen limit of detection $(0.001 \mu \mathrm{g} / \mathrm{kg})$, a procedure commonly applied for concentrations below limit of detection LOD [28]. On the other side of the scale, cymoxanil displayed the lowest Rp value, namely Rp of 1.5, which could be potentially attributed to a faster dissipation rate in the peel.

Interestingly, the pesticide residues could be classified into two distinct groups, characterized by two parameters, namely $\log \mathrm{P}$ and $\mathrm{Rp}$ (Table 3). The pesticides of the first group (cyflumetofen, difenoconazole, novaluron, and pyraclostrobin) could be characterized by a high lipophilicity ( $\log \mathrm{P} \geq 4)$ and large $R p$ value $\geq 15$ (Table 3). On the other hand, pesticides comprising the second group (boscalid, chloranthraniliprole, cymoxanil, and tetraconazole) revealed LogP values $\leq 3.5$ and $\mathrm{Rp}$ values $\leq 10$ (Table 3). Hence, it seems that the more lipophilic pesticides $(\log P \geq 4)$ tend to preferentially concentrate in the peel, while the less lipophilic pesticides $(\log P \leq 3.5)$ displayed a lower tendency to concentrate in the peel. A possible explanation for the observed phenomenon might be associated with the fact that highly lipophilic compounds are generally being more rapidly converted to more hydrophilic metabolites within an aqueous environment (e.g., plasma, intracellular and extracellular fluids), while more hydrophilic compounds display a lower metabolic conversion rate, as was previously demonstrated for pharmaceuticals [29]. Since pulp is considered an aqueous environment and the peel a more lipophilic matrix, lipophilic compounds are expected to display larger persistence on the peel than within the pulp and vice versa. 
Table 3. Average peel to pulp ratio of pesticide amount (Rp) over the entire storage time as a function of irrigation water type ("fresh" vs. "salty") ${ }^{1}$.

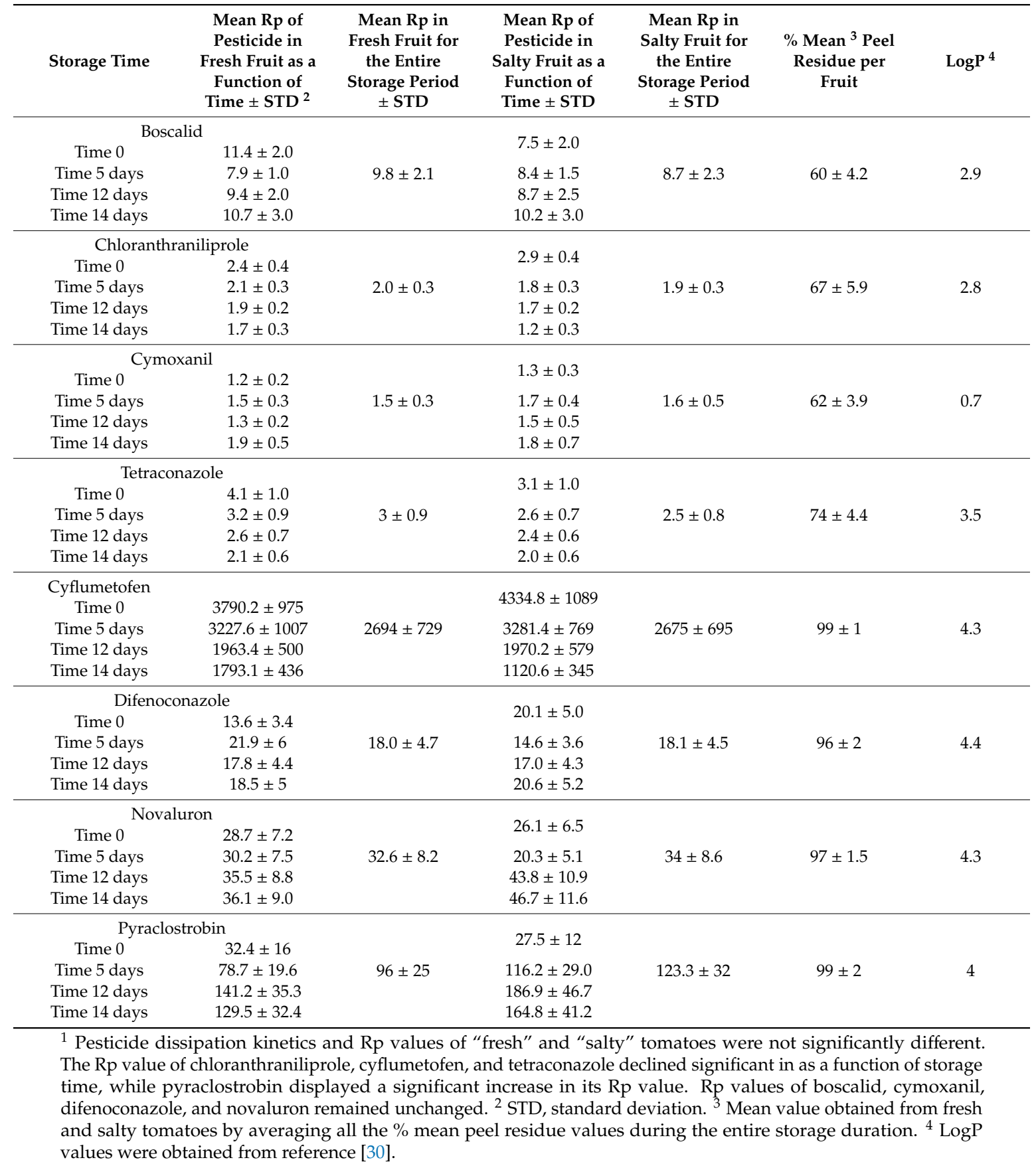

\subsection{Linear Regression of LogP Values and \% Pesticide Residue in Peel}

Simple linear regression analysis of $\log P$ values vs. \% residue in the peel of the eight detected pesticides yielded a significant slope deviation from zero $(p<0.01)$ resulting in a large $R^{2}$ of 0.67 (Figure 2). Correlating LogP vs. Log \% residue in the peel yielded similar Pearson coefficient, namely $R^{2}$ of 0.68 and slope deviation from zero at a $p<0.01$. The significant correlation between the two aforementioned parameters clearly indicates that an increase in the compound's lipophilicity directly affects its distribution ratio between peel to pulp in favor of the peel. As elaborated in the previous Section 3.2, the latter observation might be the result of a higher persistence of lipophilic pesticides in 
lipophilic matrices such as the peel, similarly to that recently found by Shimshoni et al. for lipophilic pesticides in beeswax [23].

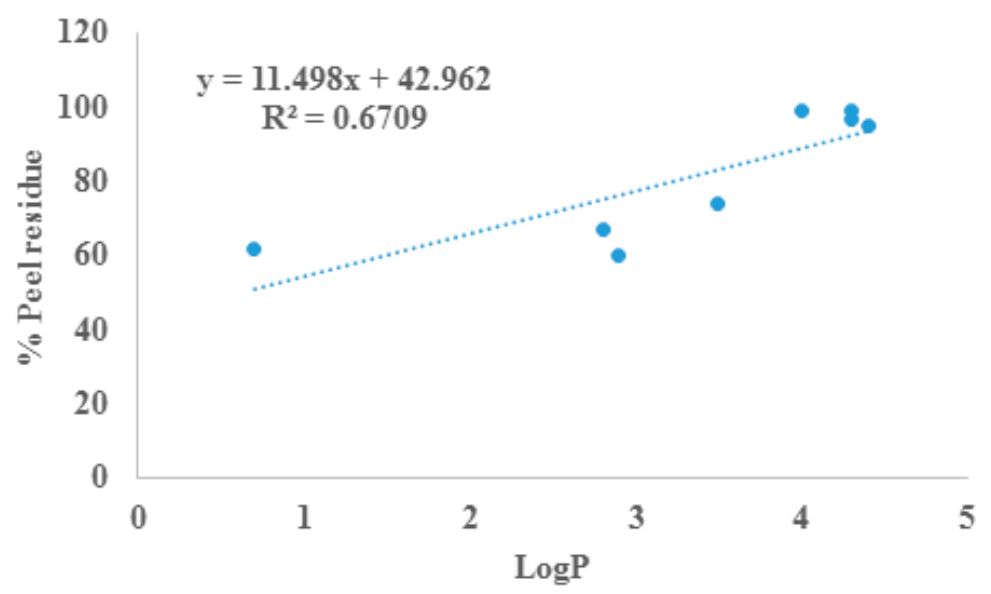

Figure 2. Correlation between $\log \mathrm{P}$ values against \% pesticide residue in peel.

\subsection{Dietary Risk Assessment of Contaminated Cherry Tomato Consumption}

All of the HQ as well as the final HI values for all of the detected pesticides were below the value of 1 for both "fresh" and "salty" tomatoes (Table 4). Consequently, assuming additivity of the HQ values, the total HI for both "fresh" and "salty" tomatoes is indicative of a negligible health risk to adults and children (Table 4).

Table 4. Hazard quotient (HQ) and hazard index (HI) for cherry tomato consumption.

\begin{tabular}{|c|c|c|c|c|c|}
\hline \multirow{3}{*}{ Pesticide } & \multirow{3}{*}{$\mathrm{MRL}^{\mathrm{a}}(\mathrm{mg} / \mathrm{kg})$} & \multicolumn{4}{|c|}{ Average Daily Intake (mg/kg/day) } \\
\hline & & \multicolumn{2}{|c|}{ Fresh Fruit } & \multicolumn{2}{|c|}{ Salt Fruit } \\
\hline & & Adults & Children & Adults & Children \\
\hline Boscalid & 3.0 & $7.06 \mathrm{E}^{-5}$ & $28.3 \mathrm{E}^{-5}$ & $6.93 \mathrm{E}^{-5}$ & $27.7 \mathrm{E}^{-5}$ \\
\hline Chloranthraniliprole & 0.6 & $0.07 \mathrm{E}^{-5}$ & $0.28 \mathrm{E}^{-5}$ & $0.12 \mathrm{E}^{-5}$ & $0.48 \mathrm{E}^{-5}$ \\
\hline Cyflumethofen & 0.3 & $0.08 \mathrm{E}^{-5}$ & $0.34 \mathrm{E}^{-5}$ & $0.12 \mathrm{E}^{-5}$ & $0.48 \mathrm{E}^{-5}$ \\
\hline Cymoxanil & 0.4 & $0.23 \mathrm{E}^{-5}$ & $0.92 \mathrm{E}^{-5}$ & $0.22 \mathrm{E}^{-5}$ & $0.90 \mathrm{E}^{-5}$ \\
\hline Difenconazole & 2.0 & $0.34 \mathrm{E}^{-5}$ & $1.37 \mathrm{E}^{-5}$ & $0.41 \mathrm{E}^{-5}$ & $1.65 \mathrm{E}^{-5}$ \\
\hline Novaluron & 1.0 & $0.56 \mathrm{E}^{-5}$ & $2.24 \mathrm{E}^{-5}$ & $0.41 \mathrm{E}^{-5}$ & $1.65 \mathrm{E}^{-5}$ \\
\hline Pyraclostrobin & 0.3 & $0.98 E^{-5}$ & $3.92 \mathrm{E}^{-5}$ & $1.19 \mathrm{E}^{-5}$ & $4.76 \mathrm{E}^{-5}$ \\
\hline \multirow[t]{2}{*}{ Tetraconazole } & 0.1 & $2.03 \mathrm{E}^{-5}$ & $8.11 \mathrm{E}^{-5}$ & $2.59 \mathrm{E}^{-5}$ & $10.4 \mathrm{E}^{-5}$ \\
\hline & & \multirow{2}{*}{\multicolumn{2}{|c|}{ Fresh fruit }} & & \\
\hline \multirow[t]{2}{*}{ Pesticide } & \multirow{2}{*}{$\operatorname{RfD}^{b}(\mathrm{mg} / \mathrm{kg})$} & & & \multicolumn{2}{|c|}{ Salt fruit } \\
\hline & & Adults & Children & Adults & Children \\
\hline Boscalid & 0.218 & $32.4 \mathrm{E}^{-5}$ & $129.6 \mathrm{E}^{-5}$ & $31.8 \mathrm{E}^{-5}$ & $127.1 \mathrm{E}^{-5}$ \\
\hline Chloranthraniliprole & 1.58 & $0.04 \mathrm{E}^{-5}$ & $0.18 \mathrm{E}^{-5}$ & $0.08 \mathrm{E}^{-5}$ & $0.30 \mathrm{E}^{-5}$ \\
\hline Cyflumethofen & 0.17 & $0.49 \mathrm{E}^{-5}$ & $1.98 \mathrm{E}^{-5}$ & $0.70 \mathrm{E}^{-5}$ & $2.80 \mathrm{E}^{-5}$ \\
\hline Cymoxanil & 0.0008 & $288.5 \mathrm{E}^{-5}$ & $1154.2 \mathrm{E}^{-5}$ & $279.8 \mathrm{E}^{-5}$ & $1119.2 \mathrm{E}^{-5}$ \\
\hline Difenconazole & 0.01 & $34.3 \mathrm{E}^{-5}$ & $137.1 \mathrm{E}^{-5}$ & $41.3 \mathrm{E}^{-5}$ & $165.1 \mathrm{E}^{-5}$ \\
\hline Novaluron & 0.011 & $50.9 \mathrm{E}^{-5}$ & $203.5 \mathrm{E}^{-5}$ & $37.5 \mathrm{E}^{-5}$ & $150.1 \mathrm{E}^{-5}$ \\
\hline Pyraclostrobin & 0.034 & $28.8 \mathrm{E}^{-5}$ & $115.2 \mathrm{E}^{-5}$ & $3.5 \mathrm{E}^{-5}$ & $139.9 \mathrm{E}^{-5}$ \\
\hline Tetraconazole & 0.0073 & $277.9 \mathrm{E}^{-5}$ & $1111.5 \mathrm{E}^{-5}$ & $354.5 \mathrm{E}^{-5}$ & $1418.2 \mathrm{E}^{-5}$ \\
\hline $\mathrm{HI}$ & & $713.3 \mathrm{E}^{-5}$ & $2853.3 \mathrm{E}^{-5}$ & $780.6 \mathrm{E}^{-5}$ & $3122.6 \mathrm{E}^{-5}$ \\
\hline
\end{tabular}

${ }^{a}$ MRL: Maximum residue limit obtained from reference [5]. ${ }^{b}$ RfD: Reference dose obtained from reference [31]. 


\section{Conclusions}

Tetraconazole was the only pesticide residue exceeding the MRL value of $50 \mu \mathrm{g} / \mathrm{kg}$ in "salty" whole fruit tomatoes (namely $55 \mu \mathrm{g} / \mathrm{kg}$ ) after 5 days of storage time. Moreover, tetraconazole exceeded the MRL in "sweet" and "salty" peels during the whole storage period. Since tetraconazole has been demonstrated to potentially impair fetal development and reproduction, it is suggested to restrict the last application of tetraconazole to not less than 56 days before harvest in order to avoid any possible deviations from the MRL value of $50 \mu \mathrm{g} / \mathrm{kg}$. The extent of pesticide peel penetrability as well as the pesticide distribution and residual levels in peel and pulp were unaffected at a salinity level of EC $1.5-3 \mathrm{ds} / \mathrm{m}$. Hence, for the aforementioned pesticides, an increased peel penetrability at a fresh water salinity level of $1.5 \mathrm{ds} / \mathrm{m}$ is not expected to occur. The most commonly applied household washing procedure for fruit and vegetable, using running tap water for $30 \mathrm{~s}$, was ineffective at removing residual pesticides from the peel. Hence, a more efficient washing procedure is required to improve consumers' safety. Furthermore, the pesticide residues could be classified according to their Rp and LogP values, as follows: Lipophilic pesticides with $\log \mathrm{P} \geq 4$ were characterized by larger Rp value and peel residue levels, while the less lipophilic pesticides $(\log \mathrm{P} \leq 3.5)$ displayed lower $\mathrm{Rp}$ and peel residue levels. Significant correlation between LogP and \% peel residue levels clearly revealed the effect of lipophilicity (expressed as $\log \mathrm{P}$ ) on the \% peel residue levels.

Supplementary Materials: The following are available online at http://www.mdpi.com/2073-4395/9/12/800/s1, Table S1: MRM transition and optimized parameters for pesticides analyzed by LC-MS/MS, Table S2: MRM transition and optimized parameters for the pesticides analyzed by GC-MS/MS with positive EI ionization, Table S3: Linear regression F-test of peel to pulp pesticide amount ratio vs. time and an unpaired two-way student's $t$-test for comparing between two linear regressions.

Author Contributions: Formal analysis, J.A.S., V.B., Y.C. and R.S.; investigation, J.A.S.; methodology, J.A.S. and S.B.; project administration, E.F.; resources, Y.K.; writing—original draft, J.A.S.; writing—review \& editing, E.F.

Funding: The authors received no funding for this work.

Acknowledgments: The authors gratefully thank Efrat Habusha, Faina Golender, and Michael Borisover for their excellent technical assistance.

Conflicts of Interest: The authors state no conflict of interest.

\section{References}

1. Figàs, M.R.; Prohens, J.; Raigón, M.D.; Fita, A.; García-Martínez, M.D.; Casanova, C.; Borràs, D.; Plazas, M.; Andújar, I.; Soler, S. Characterization of composition traits related to organoleptic and functional quality for the differentiation, selection and enhancement of local varieties of tomato from different cultivar groups. Food Chem. 2015, 187, 517-524. [CrossRef] [PubMed]

2. Ranc, N.; Muños, S.; Santoni, S.; Causse, M. A clarified position for Solanum lycopersicum var. cerasiforme in the evolutionary history of tomatoes (solanaceae). BMC Plant Biol. 2008, 8, 1-18. [CrossRef] [PubMed]

3. Ilić, Z.S.; Marinković, D.; Trajkovic, R.; Sunic, L.; Perzelan, Y.; Alkalai-Tuvia, S.; Fallik, E. Effect of 1-methylcyclopropene on the antioxidant capacity and postharvest quality of tomato fruit. Afr. J. Biotechnol. 2013, 12, 547-553.

4. Donkor, A.; Osei-Fosu, P.; Dubey, B.; Kingsford-Adaboh, R.; Ziwu, C.; Asante, I. Pesticide residues in fruits and vegetables in Ghana: A review. Environ. Sci. Pollut. Res. Int. 2016, 23, 18966-18987. [CrossRef]

5. Hernández, A.F.; Gil, F.; Lacasaña, M. Toxicological interactions of pesticide mixtures: An update. Arch. Toxicol. 2017, 91, 3211-3223. [CrossRef]

6. EU Pesticide Database. Available online: http://ec.europa.eu/food/plant/pesticides/eu-pesticides-database/ public/?event=product.resultat\&language=EN\&selectedID=116 (accessed on 10 November 2019).

7. Ketner, R.; Zamorski, R. Plant Protection Pesticides Allowed for Sale in Israel. The Ministry of Agriculture and Plant Protection Inspection Services. 2019. Available online: https://www.moag.gov.il/ppis/Yechidot/ chimistry/rishum_rishuy/pirsumim/2019/Documents/tachshirim_2019.pdf (accessed on 10 November 2019). 
8. Calvaruso, E.; Cammilleri, G.; Pulvirenti, A.; Lo Dico, G.M.; Lo Cascio, G.; Giaccone, V.; Vitale Badaco, V.; Ciprì, V.; Alessandra, M.M.; Vella, A.; et al. Residues of 165 pesticides in citrus fruits using LC-MS/MS: A study of the pesticides distribution from the peel to the pulp. Nat. Prod. Res. 2019, 19, 1-5. [CrossRef]

9. Zou, N.; Yuan, C.; Chen, R.; Yang, J.; Li, Y.; Li, X.; Pan, C. Study on mobility, distribution and rapid ion mobility spectrometry detection of seven pesticide residues in cucumber, apple, and cherry tomato. J. Agric. Food Chem. 2017, 65, 182-189. [CrossRef]

10. Lichter, A.; Dvir, O.; Fallik, E.; Cohen, S.; Golan, R.; Shemer, Z.; Sagi, M. Cracking of cherry tomatoes in solution. Postharvest Biol. Technol. 2002, 16, 305-312. [CrossRef]

11. Amichai, M.; Cohen, S.; Shemer, Z.; Golan, R.; Hizkiyahu, E. Evaluation of Tomato Cultivars under Different Growth Condition-Final Report; Ramat Negev, R.D., Ed.; Agricultural Research Center: Giza, Egypt, 2012; p. 10. (In Hebrew)

12. Bajwa, U.; Sandhu, K.S. Effect of handling and processing on pesticide residues in food-A review. J. Food Sci. Technol. 2014, 51, 201-220. [CrossRef]

13. Goren, A.; Alkalai-Tuvia, S.; Perzelan, Y.; Aharon, Z.; Ilic', Z.; Fallik, E. Harvested tomato quality and nutritional levels as affected by high temperatures in Mediterranean wholesale markets, and home or refrigerated temperatures. Adv. Hort. Sci. 2010, 24, 200-206.

14. Al-Taher, F.; Chen, Y.; Wylie, P.; Cappozzo, J. Reduction of pesticide residues in tomatoes and other produce. J. Food Prot. 2013, 76, 510-515. [CrossRef]

15. Andrade, G.C.R.M.; Monteiro, S.H.; Francisco, J.F.; Figueiredo, L.A.; Rochac, A.A.; Tornisieloa, V.L. Effects of types of washing and peeling in relation to pesticide residues in tomatoes. J. Braz. Chem. Soc. 2015, 26, 1994-2002. [CrossRef]

16. Jankowska, M.; Kaczynski, P.; Hrynko, I.; Lozowicka, B. Dissipation of six fungicides in greenhouse-grown tomatoes with processing and health risk. Environ. Sci. Pollut. Res. Int. 2016, 23, 11885-11900. [CrossRef]

17. Rodrigues, A.A.Z.; De Queiroz, M.E.L.R.; De Oliveira, A.F.; Neves, A.A.; Heleno, F.F.; Zambolim, L.; Freitas, J.F.; Morais, E.H.C. Pesticide residue removal in classic domestic processing of tomato and its effects on product quality. J. Environ. Sci. Health B 2017, 52, 850-857. [CrossRef]

18. US EPA. Supplementary Guidance for Conducting Health Risk Assessment of Chemical Mixtures; EPA/630/R-00/002; Risk Assessment Forum Technical Panel, United States Environmental Protection Agency Office: Washington, DC, USA, 2000.

19. Katz, L.; Fridkin, Z. Edible Tomatoes in Israel-Survey; Ministry of Agriculture and Rural Development, Research Economy and Strategy Division: Hanoi, Vietnam, 2014. Available online: https://www.moag.gov.il/ yhidotmisrad/research_economy_strategy/publication/2014/documents/Tomatoes_in_israel.pdf (accessed on 10 November 2019).

20. Wang, Z.; Huang, J.; Chen, J.; Li, F. Effectiveness of dishwashing liquids in removing chlorothalonil and chlorpyrifos residues from cherry tomatoes. Chemosphere 2013, 92, 1022-1028. [CrossRef]

21. EFSA Scientific Report. In Conclusion on the Peer Review of Tetraconazole; EFSA: Parma, Italy, 2008; Volume 152, pp. 1-86. Available online: https://www.efsa.europa.eu/en/efsajournal/pub/rn-152 (accessed on 10 November 2019).

22. Ministry of Agriculture Pesticide Database, Israel. Available online: http://www.hadbara.moag.gov.il/ hadbara/ (accessed on 10 November 2019).

23. Shimshoni, J.A.; Sperling, R.; Massarwa, M.; Chen, Y.; Bommuraj, V.; Borisover, M.; Barel, S. Pesticide distribution and depletion kinetic determination in honey and beeswax: Model for pesticide occurrence and distribution in beehive products. PLoS ONE. 2019, 14, e0212631. [CrossRef]

24. Yang, T.; Doherty, J.; Zhao, B.; Kinchla, A.J.; Clark, J.M.; He, L. Effectiveness of commercial and homemade washing agents in removing pesticide residues on and in apples. J. Agric. Food Chem. 2017, 65, 9744-9752. [CrossRef]

25. US EPA web-based CompTox Chemistry Dashboard. Available online: https://comptox.epa.gov/dashboard (accessed on 10 November 2019).

26. Yang, T.; Zhao, B.; Kinchla, A.J.; Clark, J.M.; He, L. Investigation of pesticide penetration and persistence on harvested and live basil leaves using surface-enhanced raman scattering mapping. J. Agric. Food Chem. 2017, 65, 3541-3550. [CrossRef]

27. Van Eerd, L.L.; Hoagland, R.E.; Zabbtowicz, R.M.; Hall, J.C. Pesticide metabolism in plants and microorganisms. Weed Sci. 2003, 51, 472-495. [CrossRef] 
28. Hornung, R.W.; Reed, L.D. Estimation of average concentration in the presence of nondetectable values. App. Occup. Environ. Hyg. 1990, 5, 46-51. [CrossRef]

29. Arnott, J.A.; Planey, S.L. The influence of lipophilicity in drug discovery and design. Expert Opin. Drug Discov. 2012, 7, 863-875. [CrossRef] [PubMed]

30. University of Hertfordshire. Pesticides Properties Database. Available online: https://sitem.herts.ac.uk/aeru/ ppdb/en/ (accessed on 10 November 2019).

31. US EPA. IRIS Assessments. Available online: https://cfpub.epa.gov/ncea/iris_drafts/atoz.cfm?list_type=alpha (accessed on 10 November 2019). 